RESIDENT

\& FELLOW

SECTION

Section Editor

Mitchell S.V. Elkind,

MD, MS

\title{
Emerging Subspecialties in Neurology: Neurocritical care
}

Asma Zakaria, MD

J. Javier Provencio, MD

George A. Lopez, MD, $\mathrm{PhD}$

Address correspondence and reprint requests to Dr. Asma Zakaria, Baylor College of Medicine, Department of Neurology, 6501 Fannin Street, NB 302, Houston, TX 77030 asmazakaria@gmail.com
Historically, neurology has been a primarily outpatient specialty. ${ }^{1}$ The advent of modern neurosurgical techniques, as well as more elegant means of artificial ventilation in the 1960s, brought increasing numbers of neurologic patients to the intensive care units (ICU). Although these patients were primarily managed by medical and surgical-anesthesiologist intensivists, occasional consults for neurophysiologic testing, management of neuromuscular failure, and, more commonly, prognostication, would bring neurologists to the ICU. In the 1980s and 1990s, the surge in new neurosurgical procedures and advances in cardiovascular disease spurred on the development of a newer, different subset of neurologist. Some developed an interest in cerebrovascular diseases, while others ventured into the ICUs and carved a niche for a new subspecialty: neurocritical care.

A small number of neurologists, anesthesiologists, neurosurgeons, and medical intensivists aimed to identify and correct the factors that were contributing to the high mortality rates in neurologic intensive care units (NICUs). Through the 1980s and 1990s, four major centers of NICU training emerged. These centers were headed by Dr. Allan Ropper at Massachusetts General Hospital, Dr. Matthew Fink at Columbia University, Dr. Thomas Bleck at University of Virginia at Charlottesville, and Dr. Dan Hanley at Johns Hopkins. ${ }^{2}$ These "Four fathers" ${ }^{\prime 3}$ of neurocritical care in the United States have trained numerous fellows who then went on to run their own ICUs across the country.

THE PRACTICE OF NEUROCRITICAL CARE TODAY Today, neurocritical care is a more established subspecialty and fellowships are awaiting United Council for Neurologic Subspecialties (UCNS) accreditation within the next year. However, this has not been an easy course. Many neurointensivists have faced challenges in part due to the competing interests of neurointensivists with neurosurgeons, neurologists, and other intensive care physicians. This has resulted in several different institution-dependent types of NICU practices.

The NICU consult service involves a team of neurointensivists who provide consultation services to neurosurgical and medical ICU patients. The primary anesthetist/medical intensivist handles ventilator management and invasive monitoring procedures.

The open NICU is probably the commonest arrangement. This involves a neurointensivist who has admitting privileges in a NICU but is not responsible for all patients in the NICU. Neurosurgeons may admit directly to the NICU and consult other medical intensivists to care for ventilated patients.

The closed NICU is the model in which all patients admitted to the NICU are primarily managed by the neurointensivist. Upon discharge from the NICU, they are attended to by the neurology or neurosurgical ward teams. Some units also take care of non-neurologic ICU spillover patients. Most procedures are handled by the NICU team.

The closed-cooperative NICU model is one in which the neurology/neurosurgery service continues to have an active role in the management of patients in the NICU (particularly in regard to family discussions and longer-term management decisions). The NICU team handles day to day issues, however, and is responsible for most procedures.

Neurology residency programs are required to have "discrete rotations in critical care" ${ }^{4}$ where residents learn to manage patients with neurologic complications of medical diseases, intracerebral hemorrhages, malignant cerebral infarctions, status epilepticus, and neuromuscular respiratory failure. With the advent of modern neurosurgical 
and neurointerventional radiology procedures, a newer face of neurology is emerging. Many residents graduating from training programs today are not exposed to this subspecialty because of the apparent nationwide dearth of NICUs. According to the "Neurologists 2004" 1 report by the American Academy of Neurology (AAN), only $11.6 \%$ of neurologists participate in some capacity in critical care and $42 \%$ in stroke management. There was no clarification of the type or extent of critical care exposure. The vast majority of neurologists $(80 \%)$ continue to pursue primarily outpatient careers. The steady growth in the number of adequately staffed NICUs has not matched the overwhelming demand for specialists in this field across the country. Similarly, new fellowship programs emerge every year, and although the number of neurology applicants increases with each academic year, this is not enough to fill all positions and is far from fulfilling the national demand. Although no statistics exist to support this contention, it appears that several neurointensivist positions remain unfilled every year. While some of this may be attributed to the type of applicants neurology residencies attract (most, perhaps, being interested in outpatient careers), this trend may also reflect the curricula of training programs in general. It is essential that program directors and the Accreditation Council for Graduate Medical Education (ACGME) incorporate rotations such as critical care into neurology residency requirements in order to provide a more rounded training experience as well as to increase exposure and interest in this field.

FELLOWSHIP TRAINING IN NEUROCRITICAL CARE Neurocritical care as a fellowship and a career has much to offer clinicians as well as scientists. We are still learning the mechanisms of cerebral perfusion and how they are disrupted in the setting of hemorrhages, ischemic strokes, and revascularization therapies. We have several monitoring devices available, but we are still learning their application in clinical medicine. In addition, we are still looking for new therapies, reviving old ones (e.g., decompressive craniectomy, induced hypothermia), and refining them to improve patient outcomes. This brings forth a large uncharted territory for both clinical and bench research as well as for clinicians who are interested in developing guidelines and practice parameters for future application. For physicians who enjoy procedures, there are ample opportunities to insert arterial and central venous catheters, ventriculostomies, endotracheal tubes, and invasive and noninvasive monitoring devices. ${ }^{5}$

The proposed curriculum for neurocritical care training programs submitted to UCNS is a comprehensive mix of neurologic, medical, and surgical ICU training. The defined fellowship will be 2 years in duration ${ }^{6}$ and include at least 1 year of ICU rotations and approximately 6 months of research. The first set of board certification examinations was administered in December 2007.

Additional information regarding job and fellowship opportunities, and the Neurocritical Care Society, can be obtained at www.neurocriticalcare.org and www.aan.com/students/awards/ fel_res.cfm.

Neurocritical care serves as a meeting ground for neurosurgery, neurointerventional radiology, neurology, stroke, and airway management and the intensivist is a crucial mediator in patient care by all of these services. There remains a shortage of well-staffed NICUs across the nation and further efforts should be made by residency programs, the AAN, and the Neurocritical Care Society to encourage trainees to consider this as an attractive professional choice.

\section{ACKNOWLEDGMENT}

The authors thank Irfan Lalani, MD, for assistance with this article.

\section{REFERENCES}

1. Henry K, et al. Neurologists 2004: AAN Member Demographic and Practice Characteristics. In: AAN Publications. Available at: www.aan.com/publications/ other/index.cfm. Accessed November 25, 2006.

2. Rowland Lewis P. A new book evokes memories of the early days of the Neuro-ICU. Neurology Today November 2005;5:37.

3. Chang C. Society keynote address 1. Past, Present and Future: Perspectives of Neurocritical Care. Synchronicity Meeting in Baltimore, MD. Neurocritical Care 2006.

4. AAN Core Curricula. Residency Core Curriculum: Critical Care and Emergency Neurology. Available at: www.aan.com. Accessed March 6, 2007.

5. Core Curriculum and Core Competencies in Neurological Intensive Care. UCNS Documents: Appendix A. Available at: www.neurocriticalcare.org. Accessed November 25, 2006.

6. Mayer SA. UCNS Update: Setting New Standards for Neurocritical Care Training and Certification. Currents. Newsletter of the Neurocritical Care Society Vol. 1:2. Available at: www.neurocriticalcare.org. Accessed: November 25, 2006. 


\section{Neurology}

\section{Emerging Subspecialties in Neurology: Neurocritical care \\ Asma Zakaria, J. Javier Provencio and George A. Lopez \\ Neurology 2008;70;e68-e69 \\ DOI 10.1212/01.wnl.0000310991.31184.c9}

This information is current as of April 28, 2008

\section{Updated Information \& Services}

References

Citations

Subspecialty Collections

Permissions \& Licensing

Reprints including high resolution figures, can be found at: http://n.neurology.org/content/70/18/e68.full

This article cites 1 articles, 0 of which you can access for free at: http://n.neurology.org/content/70/18/e68.full\#ref-list-1

This article has been cited by 1 HighWire-hosted articles: http://n.neurology.org/content/70/18/e68.full\#\#otherarticles

This article, along with others on similar topics, appears in the following collection(s):

\section{Critical care}

http://n.neurology.org/cgi/collection/critical_care

Information about reproducing this article in parts (figures,tables) or in its entirety can be found online at:

http://www.neurology.org/about/about_the_journal\#permissions

Information about ordering reprints can be found online:

http://n.neurology.org/subscribers/advertise

Neurology ${ }^{\circledR}$ is the official journal of the American Academy of Neurology. Published continuously since 1951, it is now a weekly with 48 issues per year. Copyright . All rights reserved. Print ISSN: 0028-3878. Online ISSN: 1526-632X.

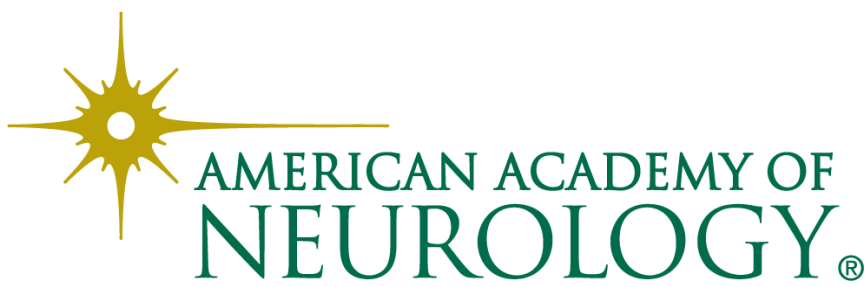

